\title{
Manufacture of all-wood sawdust-based particle board using ionic liquid-facilitated fusion process
}

\author{
Hannes Orelma ${ }^{1}$ (D) A Atsushi Tanaka ${ }^{1}$ Maija Vuoriluoto ${ }^{1} \cdot$ Alexey Khakalo $^{1}$. \\ Antti Korpela ${ }^{1}$
}

Received: 14 May 2020 / Accepted: 30 January 2021 / Published online: 16 February 2021

(c) The Author(s) 2021

\begin{abstract}
Traditional particle board can generate harmful indoor air emissions due to the volatile resin-based compounds present. This study investigated the preparation of sawdust particle board using the novel ionic liquid based fusion approach with [EMIM] OAc. The dissolution parameters were investigated using the thermal optical microscopy technique. The particle board sheets were prepared by hot pressing sawdust in the presence of ionic liquid (IL) ([EMIM]OAc) and subsequently purifying the fusion sawdust matrix from the IL with methanol. The fusion process of the sawdust particles was analysed with SEM and mechanical testing. The raw materials and the produced materials were investigated with elemental analysis, FTIR, and

${ }^{13} \mathrm{C}$-SS-NMR. IL fusion of the sawdust required a temperature above $150{ }^{\circ} \mathrm{C}$, similar to the glass transition temperature $\left(\mathrm{t}_{\mathrm{g}}\right)$ of lignin. At lower temperatures, strong particle fusion was not obtained. It was observed that the sawdust/IL weight ratio was an important parameter of the fusion process, and a 1:3 weight ratio resulted in the strongest particle boards with a tensile strength of up to $10 \mathrm{MPa}$, similar to commercial particle boards. The particle fusion process was also studied with a twin-screw extruder. The extrusion enhanced the fusion of the sawdust particles by increasing dissolution of the sawdust particles, which was subsequently seen in elevated tensile strength $(20 \mathrm{MPa})$. The study provides a practical view of how sawdust-based particle board can be manufactured using ionic liquid-based fusion.
\end{abstract}

\section{Introduction}

The forest industry produces numerous side streams from the production of wood-based products. Sawdust - a by-product of the mechanical forest industryis used in many applications, such as building materials, soil mulch, energy production (gasification, incineration, and ethanol production), and low-quality wood

Hannes Orelma

hannes.orelma@vtt.fi

1 VTT Technical Research Centre of Finland, Tietotie 4e, Espoo, Finland 
pulp (Shmulsky and Jones 2019). Particle board, with an annual production of over 100 billion cubic metres worldwide, is one of these valuable products (FAO 2017). It is made by gluing sawdust particles or wood chips using a suitable glue and a hot press system (Shmulsky and Jones 2019). Urea formaldehyde and its derivatives have been the most used synthetic resins in the industry. However, bio-based adhesives, such as tannin, lignin, vegetable oil, soy flour, and furan -based adhesives, have been under study (Pizzi 1982; Pizzi et al. 1989). One disadvantage of typical resin glued particle boards is that these composites expand strongly in water due to the hygroscopicity of lignocellulose materials, which limits their use in outdoor applications. Moreover, current formaldehyde resins are volatile (Roffael 1993) and non-biodegradable, making the manufactured particle boards partially non-biodegradable. Therefore, there is a need to find new approaches to produce sustainable particle board-type products from sawdust for more demanding applications.

Sawdust particles have a small aspect ratio compared to wood fibres, which limits their use in traditional paper and board applications. Chemically, pure sawdust is identical to native wood material. The overall chemical composition of Scots pine (Pinus sylvestris) sawdust is: cellulose $44 \%$, hemicellulose $26 \%$, lignin $26 \%$, and extractives 3\% (Rusanen et al. 2019). Pure sawdust is fully biodegradable and compostable and so produces no landfill residual waste (Eriksson et al. 2012). Sawdust particles produced at the sawmill have the same native lignin content as solid wood. Typically, wood lignin softens at temperatures above $65{ }^{\circ} \mathrm{C}$ (saturated with water) (Olsson and Salmén 1997) and reaches glass transition at above $140{ }^{\circ} \mathrm{C}$ (dry specimen) (Tejado et al. 2007). Such behaviour can be used to manufacture sawdust briquettes by compression at high temperature (Grover and Mishra 1996). This technique compacts the material, but results in a rather weak structure that is suitable only for incineration, not for building board products. Therefore, a more advanced chemistry is to fuse sawdust particle surfaces covalently and thus meet the requirements of produced materials for more advanced applications.

The monomaterial approach is a strategy to prepare a composite material without adding any adhesives. The approach is based on 'chemical welding', in which the particle surfaces are fused by both mechanical and chemical bonding so that interfaces between surfaces are eliminated. When this approach is used with cellulose materials, it is called the 'all-cellulose approach' (Nishino et al. 2004). Many cellulose solvents, such as ionic liquids, NMMO, DMaC/LiCl, NaOH-Urea, are able to chemically weld lignocellulosic materials (Graenacher 1934; Johnson 1969; Atalla and Vanderhart 1984; Nishino and Arimoto 2007). This approach was earlier utilized to fuse paperboards and bleached wood plies (Tanaka et al. 2018; Khakalo et al. 2019, 2020). Lignin-containing wood materials are more difficult to process with ILs, as the native lignin seems to be harder to dissolve than cellulose and hemicelluloses (Kilpeläinen et al. 2007). In many studies, the solubility of lignin in ionic liquids has been reported to be rather high, but many of those studies have been performed with isolated lignin samples, such as alkaline soluble kraft lignin $(\mathrm{Pu}$ et al. 2007), which poorly represents native wood lignin. It is reported that a dissolution temperature above the $\mathrm{t}_{\mathrm{g}}$ of lignin (above $150{ }^{\circ} \mathrm{C}$ ) drastically enhances dissolution ( $\mathrm{Li}$ et al. 2011). The mechanism behind this is not fully understood, but the 
behaviour is similar to the manufacture of mechanical paper pulp, where the wood material is heated above $t_{\mathrm{g}}$ to weaken the lignin bonding.

In this study, the preparation of a monomaterial composite from Scots pine sawdust using IL fusion with [EMIM]OAc (Fig. 1) was investigated. The chemical and physical material properties of the produced solid sawdust sheets were investigated, and the effect of extrusion on the partial dissolution phase was studied. The produced all-wood particle board provides a novel alternative to traditional resin glued particle boards.

\section{Experimental}

\section{Materials}

Sawdust (Scots pine) was obtained from Pölkynsaha, Finland. The obtained sawdust was fractionated with a wire (mesh size 36) to remove large particles. 1-Ethyl3-methylimidazolium acetate ([EMIM]OAc, purity 95\%, was purchased from IoLiTec GmbH, Heilbronn, Germany. All other chemicals were laboratory grade.

\section{Methods}

\section{SEM imagining}

Scanning electron microscopy (SEM) imaging was carried out with a Merlin Field Emission (FE)-SEM (Carl Zeiss NTS GmbH, Germany) with applied gold sputter coating (30 mA, $30 \mathrm{~s})$. The electron gun voltage was $3 \mathrm{kV}$ and the grid current 60 pA. The pixel resolution was fixed at $2048 \times 1536$. No image processing was used. At least three locations per each specimen were imaged.

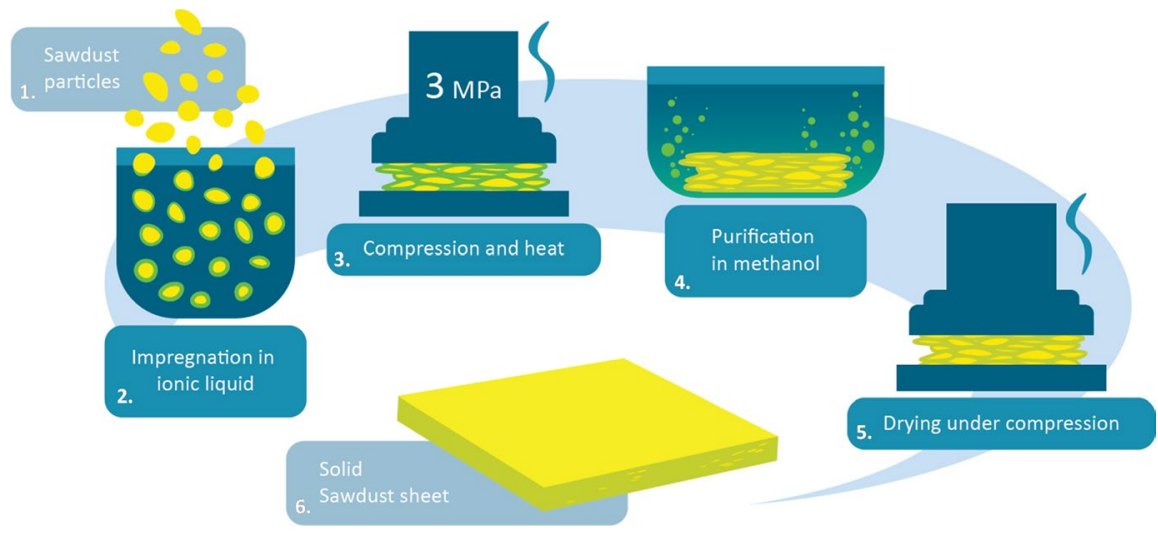

Fig. 1 Schematic illustration of the sequential manufacturing process of monomaterial sawdust particle board using partial dissolution with ionic liquids under simultaneous compression and heating, followed by regeneration and purification from ionic liquid, and drying under compression 


\section{Particle size distribution measurement with fibre analyser}

The physical characteristics of the sawdust particles were investigated using a Kajaani FS300 fibre analyser (Metso Automation Inc., Helsinki, Finland). The device is developed for fibre materials and can also measure other particle types. Particle length, width, curl, and kink index were measured optically. The measurement principle is based on the tendency of individual particles to change their light polarization as they pass through a narrow capillary. All measurements were duplicated.

\section{Analysis of the dissolution with the thermal optical microscopy imaging}

Thermal optical microscopy imaging of the sawdust particles was performed with an optical microscope Nikon H550S (Nikon camera head DS-Fi2 and Nikon DS-U3 digital camera control unit) with a $10 \times$ TU Plan Fluor objective equipped with a TMS 93 temperature programmer and a HFS 91 heating and freezing stage (Linkam Scientific Instruments Ltd., Waterfield, UK). A small amount of sawdust was mixed with [EMIM]OAc and pipetted onto microscopy glass slide and covered with another glass slide. The specimens were mounted onto the heating stage assembled to the optical microscope. The specimens were heated from ambient conditions at a rate of $40{ }^{\circ} \mathrm{C} / \mathrm{min}$ until the desired treatment temperature was reached $\left(100{ }^{\circ} \mathrm{C}\right.$, $120{ }^{\circ} \mathrm{C}$ and $140{ }^{\circ} \mathrm{C}$ ). After reaching the targeted temperature, optical microscopy images were obtained at different time intervals ( $0 \mathrm{~min}, 5 \mathrm{~min}$, and $10 \mathrm{~min}$ ). A video from the heating process to target temperature was also recorded. The imaging was performed at least in duplicate for each test point. All images were recorded with ISO sensitivity equivalent to ISO 642 using the exposure times from $130 \mu \mathrm{sec}$ to $60 \mathrm{~s}$ and an image resolution of $2560 \times 1920$ pixels.

\section{Preparation of particle board by IL fusion}

$7.5 \mathrm{~g}$ of fractioned sawdust was first mixed with $50 \mathrm{~g}$ of methanol. Then, $25 \mathrm{wt} \%$ methanol solution of IL ([EMIM]OAc) was dosed, and then, the solution was mixed thoroughly. The sawdust-IL ratios (in wt $\%$ ) were varied across five different cases: $1: 0.5,1: 1,1: 1.5,1: 2$, and 1:3. In each case, the mixture was put in an oven heated to $95{ }^{\circ} \mathrm{C}$ for $2 \mathrm{~h}$ to remove the methanol, so that a uniform sawdust-IL mixture was finally obtained. The mixture was then placed into the metal mould as shown in Fig. 2. A metal spacer ( $4 \mathrm{~mm}$ thick) was inserted between the upper and lower bodies to maintain the desired thickness.

The IL-facilitated fusion was carried out by hot-pressing at $160{ }^{\circ} \mathrm{C}$ for $3 \mathrm{~h}$. The applied pressure was $10 \mathrm{MPa}$; however, the actual effective pressure applied to the sawdust-IL mixture was lower due to the metal spacer. The used pressure was enough to maintain the constant thickness of the specimen. In hot pressing, it is ensured that the spacer touched both the upper and lower mould bodies to obtain a sheet size of approximately $70 \mathrm{~mm} \times 70 \mathrm{~mm} \times 4 \mathrm{~mm}$. The mould set was cooled at room temperature overnight. The sheet was then carefully detached from the mould and placed into methanol bath for at least $24 \mathrm{~h}$ to remove the IL. The sheet was then 


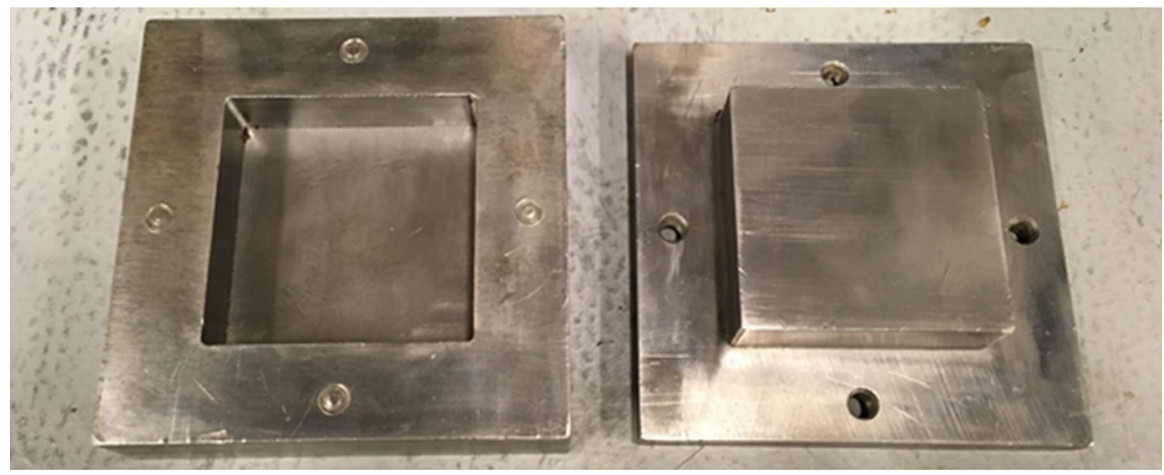

Fig. 2 Mould used in sawdust sheet making. Size of specimen: $70 \mathrm{~mm}(\mathrm{w}) \times 70 \mathrm{~mm}(1) \times 20 \mathrm{~mm}(\mathrm{~h})$

air-dried overnight under $1 \mathrm{~kg}$ weight and finally hot plate dried at $120^{\circ} \mathrm{C}$ for $5 \mathrm{~min}$ (L\&W Rapid dryer). All sample points were at least triplicated.

\section{Extrusion processing of IL-impregnated sawdust}

Sawdust strands were prepared with a twin-screw compounding machine (MicroCompounder, DACA Instruments, USA), which can offer precise control of mixing temperature and speed (Fig. 3). In the same way as sawdust sheet production by IL fusion, the sawdust was mixed with a methanol solution of IL ([EMIM]OAc) and placed in a $95{ }^{\circ} \mathrm{C}$ oven to remove the methanol and achieve a uniform sawdust-IL mixture. The mixing screw of the compounder was rotated at a fixed speed of $100 \mathrm{rpm}$. The mixture was manually introduced to the compounder using a filling tool with a funnel. Processing temperature $\left(100-220^{\circ} \mathrm{C}\right)$ and time were varied to find suitable conditions for extrusion through the nozzle ( $2 \mathrm{~mm}$ diameter). The extruded strands were finally washed in methanol, followed by air-drying at $23{ }^{\circ} \mathrm{C}$, $50 \%$ RH. At least three repetitions were done per each sample point.

\section{IL retention in all-wood particle boards}

Retention of IL in the manufactured particle boards was determined by elemental analysis. The elemental analyses $(\mathrm{C}, \mathrm{H}, \mathrm{N}, \mathrm{S})$ were performed using the FLASH 2000 (Thermo Scientific, USA) analyser after drying the specimen at $105{ }^{\circ} \mathrm{C}$ for $16 \mathrm{~h}$ to remove excess moisture. All measurements were at least duplicated.

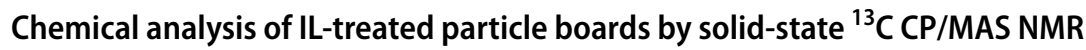 and Fourier-transform infrared (FTIR) spectroscopies}

Changes in the crystallinity of the sawdust after [EMIM]OAc treatment were characterized using a ${ }^{13} \mathrm{C}$ cross-polarization magic angle spinning (CP-MAS) NMR spectrometer (Bruker AVANCE-III $400 \mathrm{MHz}$, Bruker BioSpin, Germany). All 

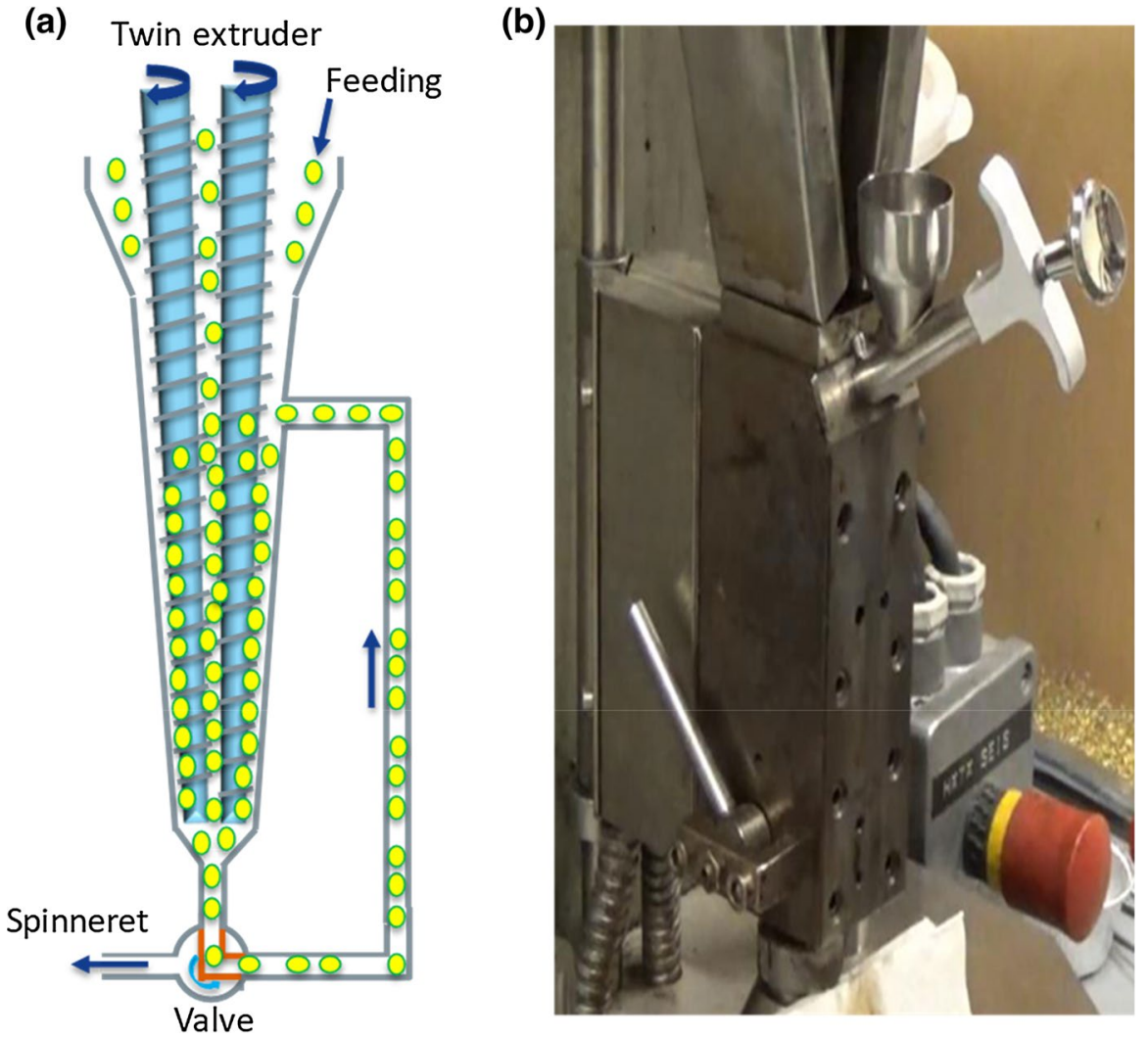

Fig. 3 a Schematic illustration of the working principle of the twin-screw compounding machine (MicroCompounder, DACA Instruments, USA). b Photograph of the twin-screw compounding machine

specimens were characterized with 20,000 scans collected using an $8 \mathrm{kHz}$ spinning frequency, 2-ms contact time, and a 5-s delay between pulses.

FTIR spectroscopy was used to study the prepared all-wood particle boards. The characterization was performed using a Thermo Scientific Nicolet iS50 FT-IR spectrometer with an ATR diamond (Thermo Scientific, USA). All spectra were obtained from 32 scans with a resolution of $4 \mathrm{~cm}^{-1}$ and absorption mode using a wavelength range of $400-4000 \mathrm{~cm}^{-1}$. At least three repetitions per specimen were conducted.

\section{Tensile strength, density, shore hardness, and water absorption of all-wood particle boards}

The mechanical strength of the prepared materials was measured with a Lloyd LS5 tensile tester equipped with a $100 \mathrm{~N}$ sensor (AMETEK Measurement \& Calibration Technologies, Florida, USA) in standardized laboratory conditions (50\% relative humidity and $23{ }^{\circ} \mathrm{C}$ temperature). At least five different filaments for each sample point were measured. The specimen size was $5 \mathrm{~mm}(\mathrm{w}) \times 40 \mathrm{~mm}(\mathrm{~L})$. 
Density of the prepared fusion material was measured gravimetrically. The dimensions of the specimens were measured as accurately as possible with a calliper. Density was calculated by dividing the mass of the specimen by the volume (calculated from the dimensions of the sample) and taking the average density of six specimens.

Shore hardness of the prepared specimens was measured with a Shore D durometer (Sauter HB, Kern \& Sohn GmbH, Germany). The shore D hardness was an average of five repetitions per each sample point. No sample pre-treatment was performed prior to the measurements.

Water absorption of the fused sawdust specimens was measured gravimetrically. Conditioned specimens (size approximately $1 \mathrm{~cm} \times 1 \mathrm{~cm}$ ) were immersed in water for $20 \mathrm{~h}$. Excess water was drained from the specimens, and the wet weight of the specimens was determined. The specimens were oven-dried at $105{ }^{\circ} \mathrm{C}$ for $24 \mathrm{~h}$, cooled in a desiccator, and immediately weighed. Water absorption was calculated based on wet and dry weights. The average water absorption values were calculated based on three repetitions per each sample point.

\section{Results and discussion}

\section{Characterization of the utilized sawdust}

The raw sawdust was mechanically screened to remove any large, several-millimetre sized, particles that could make it difficult to form uniform structures by IL fusion. Figure 4a shows a photograph of the screened sawdust used in the IL fusion studies. The photograph shows the material to be rather uniform, but in the SEM image (Fig. 4b), one can see that the used sawdust contained a wide range of irregular size particles and clear wood cell wall fragments ranging in size from 10 to $1500 \mu \mathrm{m}$. Moreover, some of the observed fragments were porous. As sawdust briquettes are widely used for household heating, it was initially tested whether the sawdust could
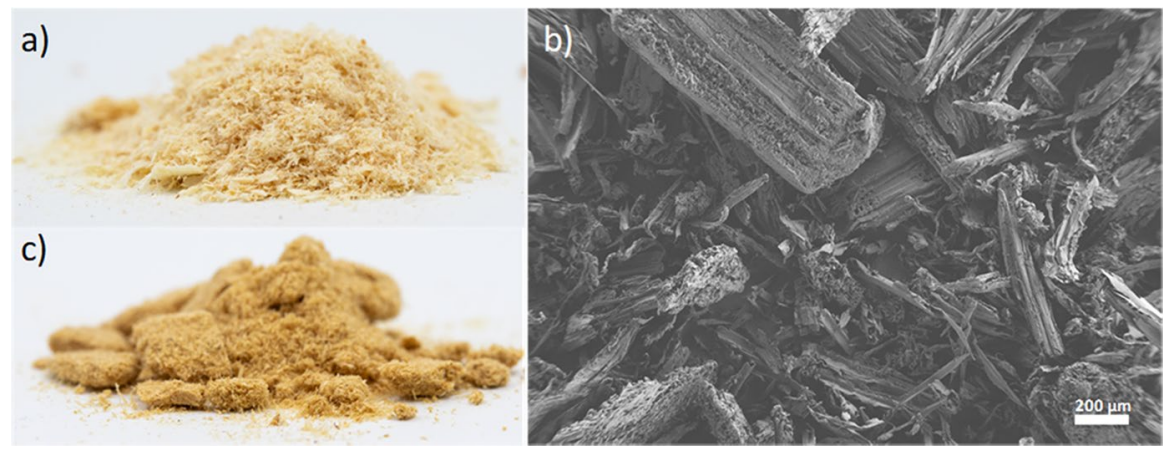

Fig. 4 a Photograph and scanning electron microscopy image of the screened sawdust used in the study. b Photograph of the screened sawdust compressed without IL; compression pressure $10 \mathrm{MPa}$, temperature $160^{\circ} \mathrm{C}$, and compression time $3 \mathrm{~h}$. c SEM image of the screened sawdust used in the study 
be compacted into a solid sheet under conditions of $10 \mathrm{MPa}$ (maximum pressure of the hot press used) and $160{ }^{\circ} \mathrm{C}$. The test found the sawdust to be loosely compacted, as the pressure is not high enough to solidify the sawdust to a degree similar to commercially manufactured sawdust briquettes (pressure $>20 \mathrm{MPa}$ ) (Mitchual et al. 2013). In commercial briquette pressing, high pressure combined with elevated temperature liquefies the lignin, which glues the sawdust forming a solid briquette.

The size distribution of the sawdust particles was investigated using a wet particle size analyser. As Fig. 5(a) and (b) shows 95\% of particles were below $1000 \mu \mathrm{m}$ in size, and the arithmetic mean length and width of the particles were $330 \mu \mathrm{m}$ and $18 \mu \mathrm{m}$, respectively. Screening effectively removed large, millimetre-sized particles typically present in sawdust (Vítěz and Trávníček 2010). The screened sawdust contained approximately $78 \%$ fines particles below $200 \mu \mathrm{m}$ in size.

\section{Temperature and time dependency of the dissolution of sawdust with [EMIM]OAC}

The dissolution of sawdust at different temperatures $\left(100{ }^{\circ} \mathrm{C}, 120{ }^{\circ} \mathrm{C}\right.$, and $140{ }^{\circ} \mathrm{C}$, respectively) as a function of time (0-10 $\mathrm{min})$ was investigated utilizing thermal optical microscopy imaging (Fig. 6). The sawdust specimens in ionic liquid [EMIM] OAc were heated at a rapid rate $\left(40^{\circ} \mathrm{C} / \mathrm{min}\right)$ from room temperature to the desired monitoring temperature. Images of the specimens were taken before heating and as the targeted temperature was reached $(0 \mathrm{~min})$. In the initial images $\left(25^{\circ} \mathrm{C}\right)$, the sawdust particles all seemed similar. In the case of the sawdust specimen at $100{ }^{\circ} \mathrm{C}$ (0 min), some smaller sawdust particles had started to react with the IL and exhibited some yellowish colour. This is likely due to the variation in dimensions of the sawdust particles as the IL probably penetrated smaller particles more rapidly than larger ones. Overall, all of the sawdust specimens contained some air trapped inside the wooden matrix of the particles observed as black areas in the images before heating (Fig. 6). Upon heating to targeted temperature points $\left(100-140{ }^{\circ} \mathrm{C}\right)$, the sawdust

(a)

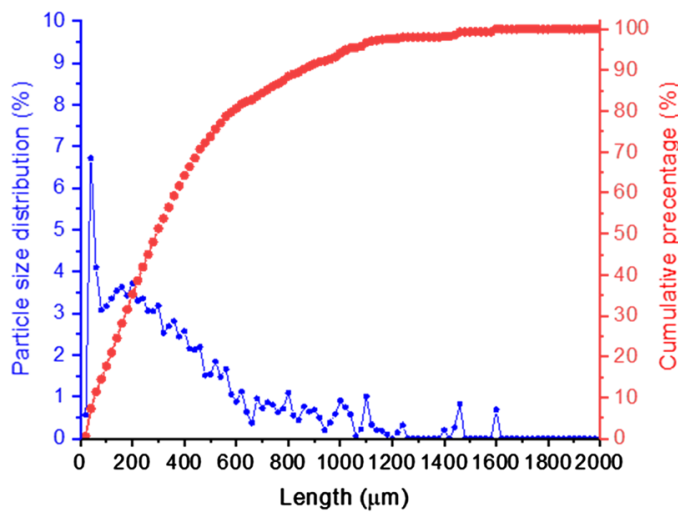

(b)

\begin{tabular}{|c|c|}
\hline Pa ra meter & Result \\
\hline Arithmetic av. fibre length (mm) & 0.33 \\
\hline $\begin{array}{l}\text { Length weighted av. fibre length } \\
\qquad(\mathrm{mm})\end{array}$ & 0.41 \\
\hline $\begin{array}{l}\text { Weight weighted av. fibre length } \\
\qquad(\mathrm{mm})\end{array}$ & 0.53 \\
\hline Fiber curl (\%) & 8.7 \\
\hline Kink index $(1 / \mathrm{m})$ & 2054 \\
\hline Fiber width $(\mu \mathrm{m})$ & 18.7 \\
\hline Fibrillation (\%) & 2.65 \\
\hline Length $<0.2 \mathrm{~mm}(\%)$ & 77.7 \\
\hline Fines A (flakelike) (\%) & 55.9 \\
\hline Fines B (lamellar) (\%) & 0.00 \\
\hline
\end{tabular}

Fig. 5 a Particle size distribution of the screened sawdust (particle size distribution and cumulative percentage). b Physical properties of the screened sawdust 


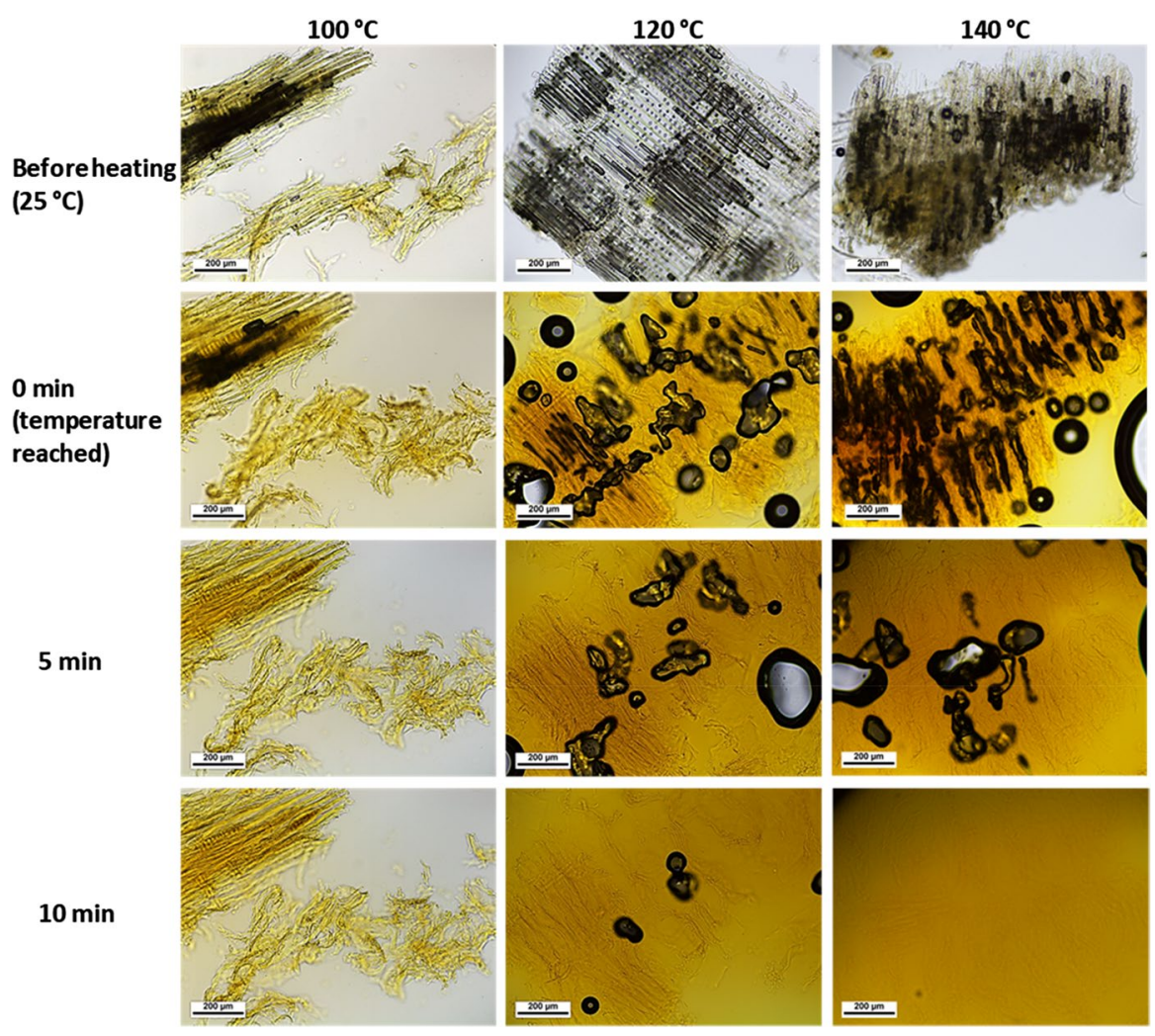

Fig. 6 Optical microscopy images of the dissolution of sawdust at three temperatures (100, 120, and $140{ }^{\circ} \mathrm{C}$ ) as a function of treatment time. The first row of images shows the specimens before heating, while the other rows show the specimens at different times after reaching the target temperature. The black colour in the images is air inside sawdust particles that is released when the system temperature raises over $100{ }^{\circ} \mathrm{C}$

specimens exhibited different behaviour in relation to elapsed time. With the temperature test point of $100{ }^{\circ} \mathrm{C}$, the sawdust specimen appeared swollen and increased in size at $0 \mathrm{~min}$, while the wood structure was still clearly observed in the particle. A slightly more yellowish colour was also observed in the image, most probably due to some partially dissolved cellulosic material released from the specimen. As the treatment time increased to $5 \mathrm{~min}$ and $10 \mathrm{~min}$, the yellow colour of the image increased, likely indicating the release of more dissolved material into the surroundings at $100{ }^{\circ} \mathrm{C}$. However, the material appeared to remain particle-like throughout the duration of the experiment, suggesting that the selected temperature of $100{ }^{\circ} \mathrm{C}$ was not sufficient to disrupt the lignin bonding $\left(\mathrm{t}_{\mathrm{g}}>150{ }^{\circ} \mathrm{C}\right)(\mathrm{Li}$ et al. 2011) of the material and thus break the structure of the sawdust particles (Fig. 6).

As the sawdust specimen was heated to $120^{\circ} \mathrm{C}$, significantly pronounced partial dissolution and swelling of the material could be observed at 0 min, displaying a vivid yellow colour and increase in particle size (Fig. 6). In spite of the extensive 
swelling, the sawdust particle structure could still be observed from the image. The black areas observed in the images were air released from the wooden matrix of the particle. As the treatment time increased to $5 \mathrm{~min}$, the structure of the sawdust particle became less distinct and the black areas in the image were reduced, indicating that the material continued to dissolve and swell at $120{ }^{\circ} \mathrm{C}$ as time elapsed and more trapped air was released due to the somewhat broken wood structure. After $10 \mathrm{~min}$ at $120{ }^{\circ} \mathrm{C}$, even less structured particle areas were observed in the image and only a small amount of air was observed in the image. This behaviour suggests that the increased temperature from $100{ }^{\circ} \mathrm{C}$ to $120{ }^{\circ} \mathrm{C}$ increased the ability of the IL to disrupt the lignin bonding of the sawdust particle but was still insufficient to fully dissolve the particle after $10 \mathrm{~min}$.

When $140{ }^{\circ} \mathrm{C}$ was reached $(0 \mathrm{~min})$ in the thermal optical microscope experiments, the sawdust specimen appeared quite similar to the previous specimen heated to $120^{\circ} \mathrm{C}$ at $0 \mathrm{~min}$. However, when treatment time increased to $5 \mathrm{~min}$, a significantly more rapid dissolution of the sawdust could be observed at $140{ }^{\circ} \mathrm{C}$ than at $120{ }^{\circ} \mathrm{C}$, as less structured particle areas were visible in the image. Furthermore, at $10 \mathrm{~min}$ $\left(140{ }^{\circ} \mathrm{C}\right)$, the sawdust particle appeared to be completely dissolved by the ionic liquid as no clearly structured areas remained in the image and all of the air had been released from the system. This suggests that the temperature of $140{ }^{\circ} \mathrm{C}$ was sufficient and close enough to the $\mathrm{t}_{\mathrm{g}}$ of lignin to disrupt the lignin bonding of the sawdust particle and dissolve the material after $10 \mathrm{~min}$. These thermal-optical microscopy experiments indicated that the rate of dissolution of the sawdust material was significantly controlled by the treatment temperature. With increasing temperature, the time required to partially dissolve and swell the material was reduced. Complete dissolution of the sawdust was possible only at sufficiently high temperature.

\section{Preparation of IL fusion sawdust sheets}

The preparation of the IL-fusion sawdust sheets was started by using the stationary partial dissolution method. Sawdust and [EMIM]OAc (hereafter IL) with a co-solvent were premixed using different sawdust/IL ratios. The co-solvent (methanol) decreased the viscosity of the solution, enabling even mixing. The use of a co-solvent does not influence the dissolution process as it evaporates at elevated temperature, as shown earlier (Tanaka et al. 2018). Different hot press temperature settings from 25 to $180{ }^{\circ} \mathrm{C}$ and sawdust-IL ratios from 1:0.5 to 1:3 were tested. It was observed that clear IL fusion took place when the temperature was above $140{ }^{\circ} \mathrm{C}$. The $160{ }^{\circ} \mathrm{C}$ temperature was an optimal compromise that produced a good fusion reaction without a significant burning of the specimens (Fig. 7a). The hot press studies correlate well with the results obtained with the optical microscopy studies shown above. However, it is important to note that the microscopy studies were carried out with a large excess of the IL that may influence the observed dissolution behaviour compared to moulding studies where the IL amount was more limited. Lignin has a glass transition point of ca. $150{ }^{\circ} \mathrm{C}$, and it has been reported earlier that rapid dissolution takes place above the $t_{\mathrm{g}}$ of lignin ( $\mathrm{Li}$ et al. 2011). Therefore, it is conceivable that lignin limits the fusion 
a)
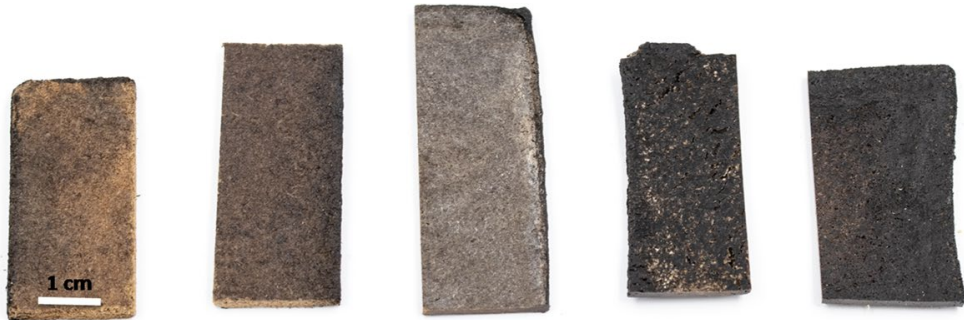

SD:IL ratio 1:0.5

1:1

1:1.5

1:2

1:3

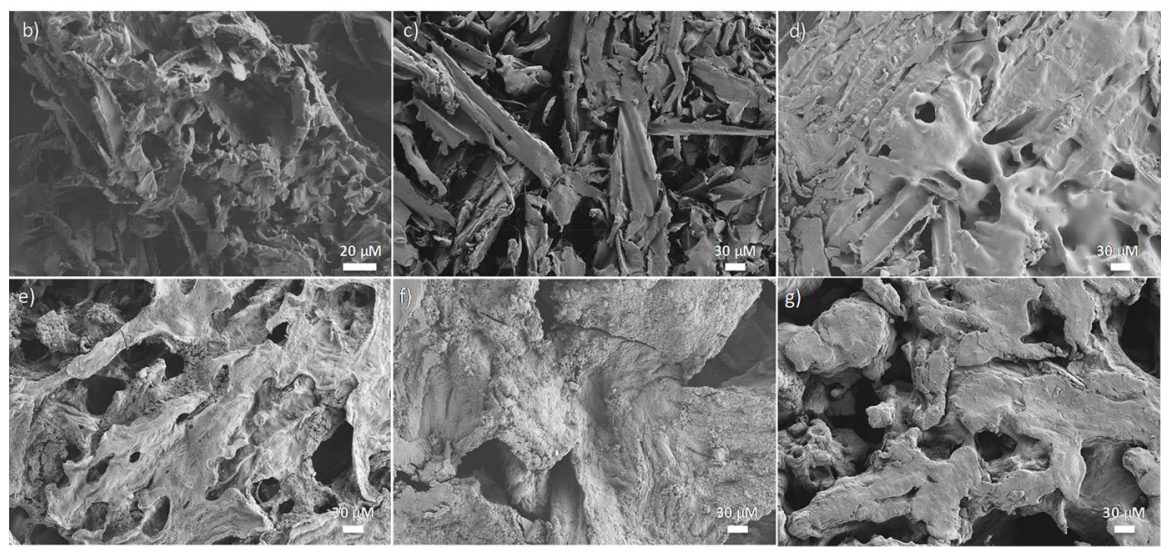

Fig. 7 a Photographs of the sawdust sheets fused with [EMIM]OAc with varying sawdust:IL weight ratios from 1:0.5 to 1:3. SEM images of sawdust particles IL-fused at different cellulose:IL ratios: $\mathbf{b}$ reference, c 1:0.5, d 1:1, e 1:1.5, f 1:2, and $\mathbf{g} 1: 3$. All samples were pressed at $160^{\circ}$ temperature

of sawdust, since both cellulose and hemicellulose are easily dissolved in ILs at lower temperatures (Kilpeläinen et al. 2007). The sawdust/IL ratio significantly influenced the mechanical properties of the prepared sheet (Fig. 7a). A 1:3 ratio clearly created the hardest structure, whereas the 1:0.5 ratio resulted in a soft structure. A possible reason for this is that the IL volume must be high enough to ensure that the IL uniformly covers all sawdust particles. The present findings are in line with a previous study of IL fusion of sawdust, in which a weight ratio of 1:2.5 was used (Croitoru and Patachia 2014).

The fusion of sawdust particles with IL was investigated using SEM. The original sawdust particles had a varying shape factor, and the size of the particles varied (Fig. 7b). When IL was present, the sawdust particles were clearly fused together ( Fig. 7c-g). One can see that the fusion strength correlates with the volume ratio. Clearly, the amount of IL needs to be high enough to ensure that there is enough dissolved material for fusion of the sawdust particles. A possible reason is that a higher volume enables the dissolution of more wood components (cellulose, hemicellulose, and lignin), which glue the structure during the regeneration phase. It is reported that the maximal cellulose concentration soluble in pure [EMIM]OAc is 25-27\% (Le et al. 2014). In traditional wood fibre reinforced 
composites, the matrix material volume needs to be high enough (typically 20-30 V\%), but not too high, so that the dispersed particles are evenly wetted to achieve a continuous composite structure with maximal strength (Gholampour and Ozbakkaloglu 2020).

\section{Enhanced dissolution of sawdust particles by extrusion}

The effect of mechanical shearing on the partial dissolution of sawdust particles was tested using a micro-extruder. Mechanical shearing inputs mechanical energy to the treated material (Abeykoon et al. 2014); this was expected to ease the penetration of IL, thus enhancing the dissolution process. However, the tests showed that processing sawdust in IL with the extruder is more demanding due to the processing conditions as the sawdust-IL suspension is required to flow through a narrow channel. The sawdust passed through the extruder only with a 1:3 sawdust-IL weight ratio. Lower IL contents stuck in the coils of the extruder. A similar temperature level $\left(150{ }^{\circ} \mathrm{C}\right)$ to the one in the hot press study was required to obtain a solid particle fusion $\left(160{ }^{\circ} \mathrm{C}\right)$. The extruded strand was uniform and purified in a similar manner to the IL-fused board. Fig. 8a, b shows a cross section of the IL-fused sawdust strand after purification. It can be seen that the sawdust particles had a solid structure, and no particle separation, as found with the stationary produced panels, was observed. The effect is more evident from the surface images ( Fig. 8c, d), which show the
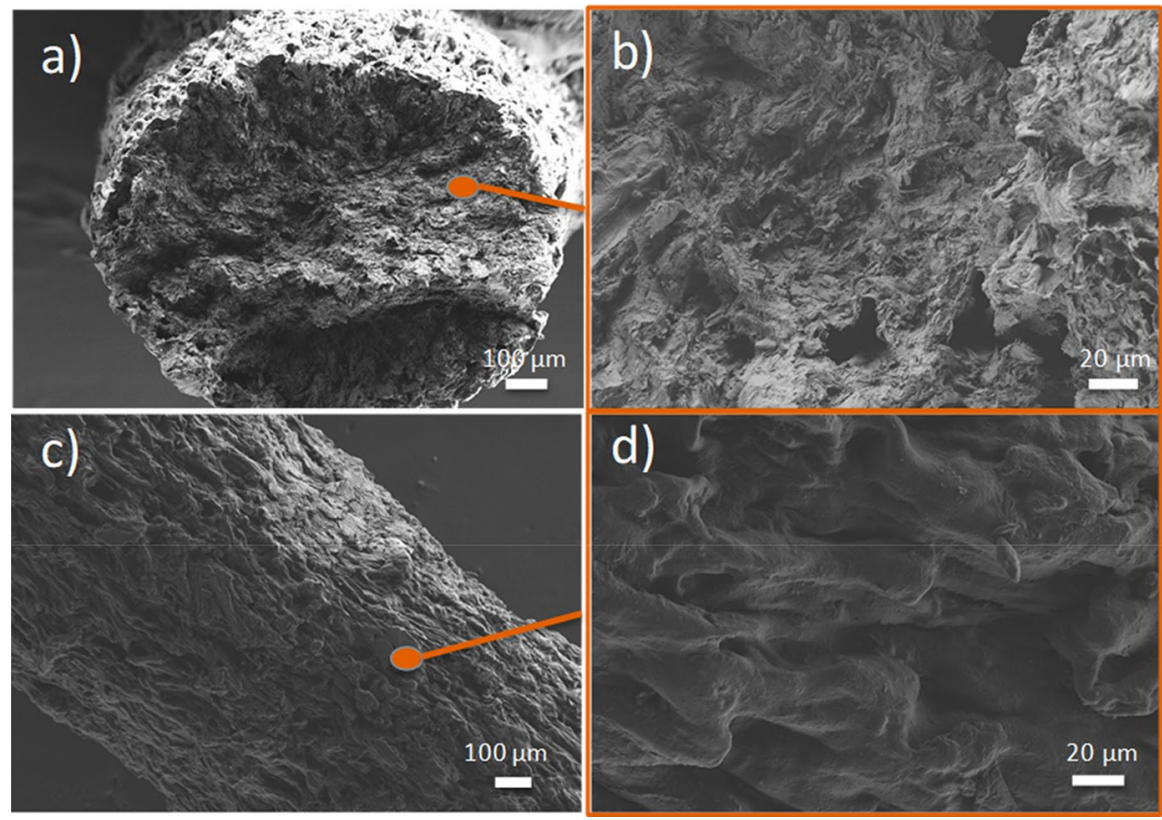

Fig. 8 SEM images of extruded IL-fused sawdust strands at a $160{ }^{\circ} \mathrm{C}$ temperature: a and b cross-sectional views at different magnifications; $\mathbf{c}$ and $\mathbf{d}$ surface views at different magnifications 
surface to be evenly coated with dissolved material. Extruders are already utilized commercially for the dissolution of cellulose in the manufacture of textile fibres in the LyoCell process from highly cellulosic dissolving pulp (Woodings 2001).

\section{Chemical analyses of the produced particle boards}

The FTIR technique was used to investigate chemical changes in the sawdust after IL fusion ( Fig. 9a). All FTIR spectra were rather similar, exhibiting all main peaks of lignocellulosic materials (Pandey and Pitman 2003). Pure cellulose exhibits a typical cellulose fingerprint region (800-1200 $\mathrm{cm}^{-1}$ ) (Fan et al. 2012). The peak at $1150 \mathrm{~cm}^{-1}$ resulted from asymmetric stretching $(\mathrm{C}-\mathrm{O}-\mathrm{C})$, and the peak at around $1000 \mathrm{~cm}^{-1}$ resulted from $\mathrm{C}-\mathrm{C}, \mathrm{C}-\mathrm{OH}, \mathrm{C}-\mathrm{H}$ glucose ring and side group vibrations. The broad band in the $3600-3,100 \mathrm{~cm}^{-1}$ range is due to the $\mathrm{OH}$-stretching vibration of the hydroxyl groups on the cellulose backbone, although bound water also contributes to this region. The aromatic skeleton of lignin has a peak at $1462 \mathrm{~cm}^{-1}$ and $\mathrm{C}-\mathrm{H}$ deformation in lignin and carbohydrates at $1425 \mathrm{~cm}^{-1}$. This indicates that partial dissolution has not caused permanent changes to the chemical structures of the chemical components of wood.

C13 CP/MAS NMR characterization was utilized to investigate the changes in the cellulose crystallinity during IL treatment. The method is widely utilized to study the crystalline structure of cellulose (Isogai et al. 1989; Foston 2014). The pure sawdust exhibited a spectrum typical for pure cellulose (cellulose I) ( Fig. 9b). The major cellulose peaks for wood cellulose are at $60.3 \mathrm{ppm}$ (C6), $74.1 \mathrm{ppm}$ (C2), $75.1 \mathrm{ppm}$ (C3), $75.8 \mathrm{ppm}$ (C5), $78.8 \mathrm{ppm}$ (C4), and $102.3 \mathrm{ppm}$ (C1), and lignin and hemicellulose have peaks at $55.7 \mathrm{ppm}$ and $63.3 \mathrm{ppm}$, respectively (Lahaye et al. 2003; Kilpeläinen et al. 2007). When the sawdust was treated with IL, at elevated temperature a clear transition from cellulose I polymorph to cellulose II was observed. The IL-treatment was stronger when the volume of the used IL increased. At a 1:3 weight ratio, the cellulose I signal almost totally vanished. The use of extrusion with IL-treatment caused significantly stronger cellulose II formation than oven treatment. These results are in accordance with the strength results (Fig. 10), that higher free IL volume creates a stronger plate. The 1:0.5, 1:1 and 1:1.5 sawdust:IL weight ratios resulted in a poor fusion strength. The effect of ionic liquid treatment on the structure of lignin has been studied earlier elsewhere (Wen et al. 2014).

Elemental analysis was used to study the purification of the IL-fused particle board. Nitrogen atoms are not naturally present in wood components, and this can thus be used as a fingerprint for [EMIM]OAc. The nitrogen content of the IL-fused specimens varied from 0.6 to $3.1 \%$ ( Table 1). This means that there was a small fraction of IL still present that was not washed out from the specimen during the purification with methanol. The lowest nitrogen content was observed in the 1:0.5 specimen, indicating that the porous specimen was more easily purified from IL. In contrast, the dense 1:3 weight ratio specimen was more difficult to wash the IL out. Moreover, it is conceivable that methanol is not an ideal solvent for [EMIM]OAc, and other polar solvents, such as water, could give a better 


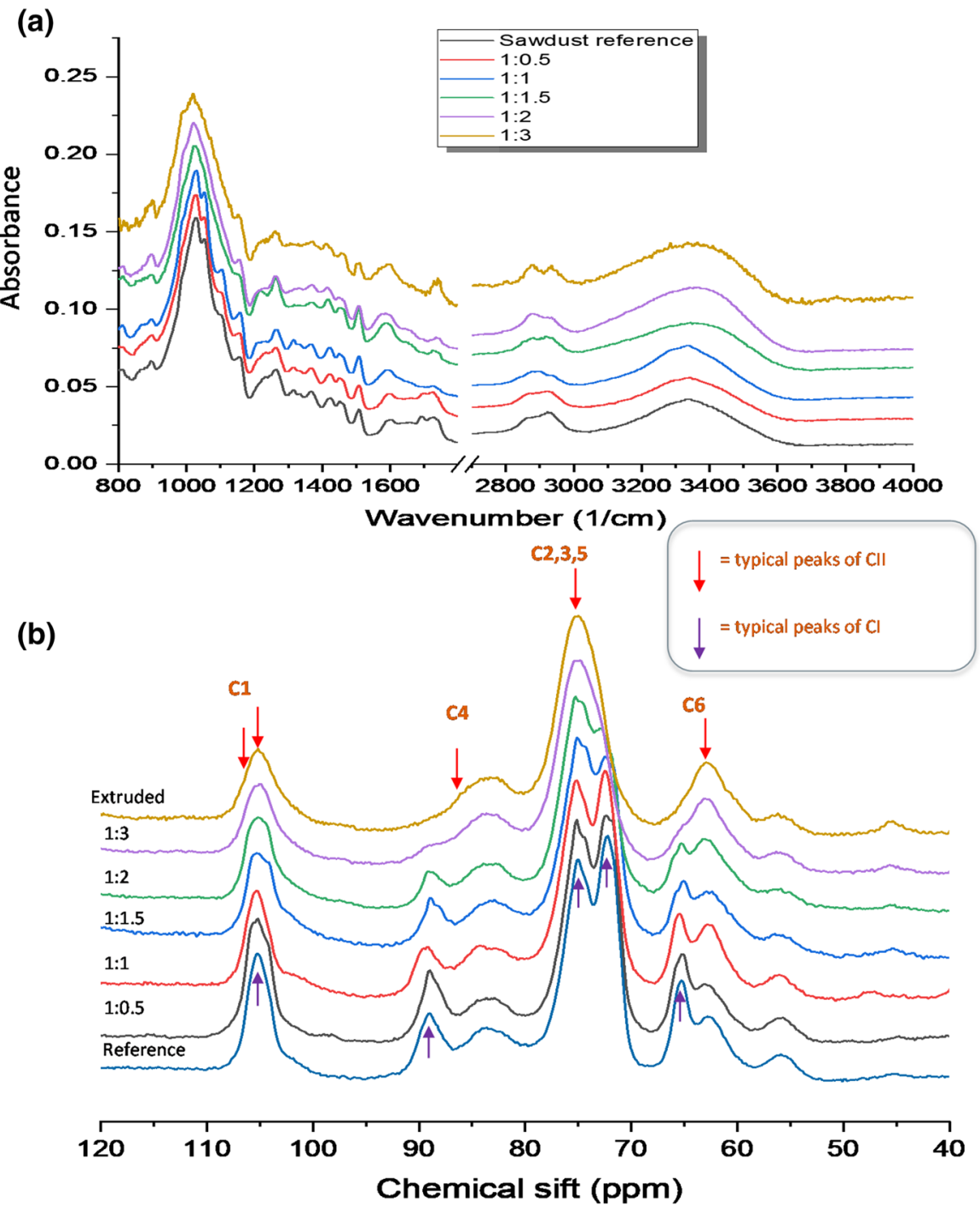

Fig. 9 a FTIR spectra of sawdust with and without fusion with IL with varying sawdust:IL ratios. $\mathbf{b}^{13} \mathrm{C}$ CP/MAS NMR spectra of sawdust before and after IL treatment with sawdust:IL weight ratios from $1: 0.5$ to $1: 3$. The NMR spectrum of sawdust treated with IL (1:3 weight ratio) in a micro extruder is also included. Arrows above and below the spectra indicate the characteristic peaks of cellulose I and II, where the main changes took place

purification result. Water swells cellulose materials strongly that helps to wash used IL out of the sample. The carbon and hydrogen contents of the pure and ILtreated sawdust specimens were similar to the reference (Ulloa et al. 2009) indicating that no substantial changes in the chemical composition occurred. 
(a)
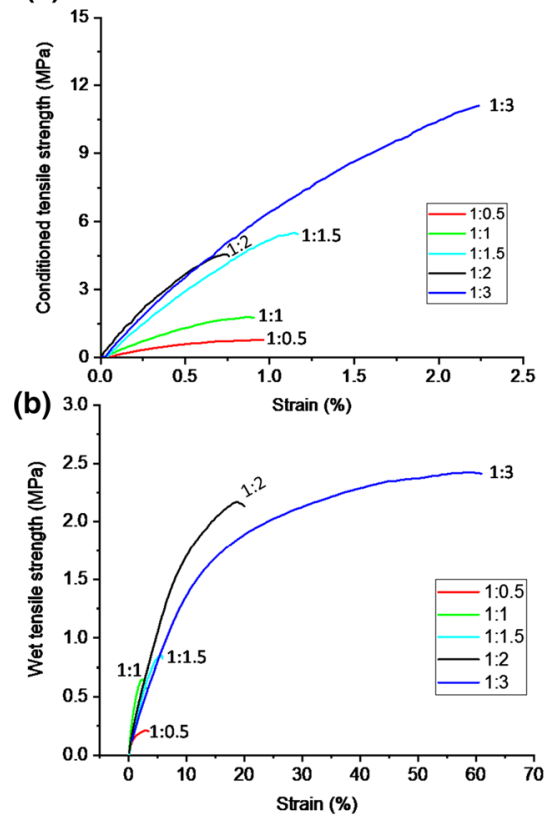

(c)

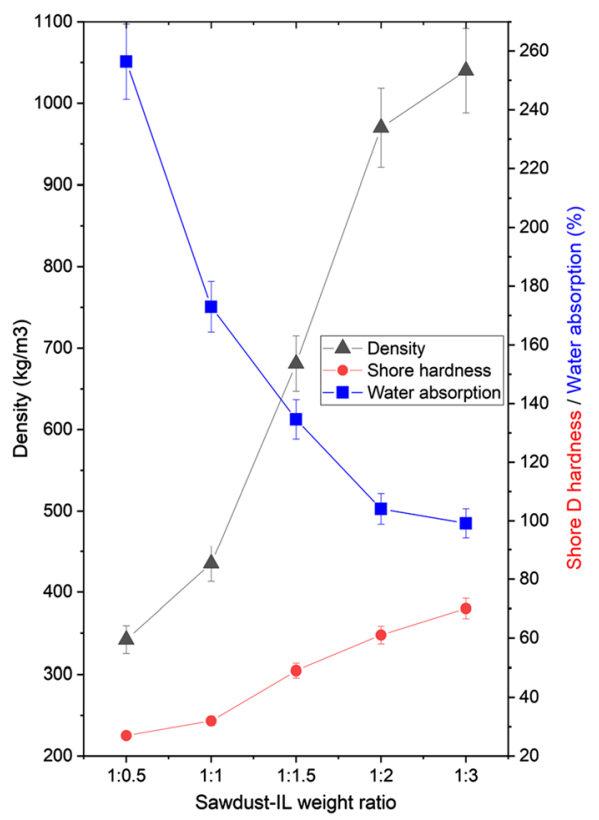

Fig. 10 Conditioned $\mathbf{a}$ and wet $\mathbf{b}$ tensile strength as a function of strain of the IL-fused sawdust sheets with varying sawdust:IL weight ratios. c Density, Shore D hardness, and water absorption of the IL-fused sawdust sheets with varying sawdust:IL weight ratios

Table 1 Elemental composition of the fused sawdust sheets as a function of sawdust:IL weight ratio

\begin{tabular}{|c|c|c|c|c|c|c|}
\hline \multirow[t]{2}{*}{ Elements (\%) } & \multicolumn{6}{|c|}{ Sawdust: ionic liquid weight ratio } \\
\hline & Reference & $1: 0.5$ & $1: 1$ & $1: 1.5$ & $1: 2$ & $1: 3$ \\
\hline Nitrogen & $\mathrm{Na}$ & $0.6 \pm 0.1$ & $0.9 \pm 0.1$ & $0.8 \pm 0.1$ & $1.2 \pm 0.1$ & $3.1 \pm 0.1$ \\
\hline Carbon & $51.6 \pm 0.1$ & $50.4 \pm 0.1$ & $50.9 \pm 0.1$ & $49.8 \pm 0.4$ & $50.7 \pm 0.2$ & $51.6 \pm 0.2$ \\
\hline Hydrogen & $6.0 \pm 0.1$ & $6.2 \pm 0.1$ & $6.2 \pm 0.1$ & $6.1 \pm 0.1$ & $6.3 \pm 0.1$ & $6.5 \pm 0.1$ \\
\hline
\end{tabular}

\section{Mechanical properties of the produced particle boards}

The mechanical performance of the produced IL-fused particle board was investigated with dry (conditioned) and wet (swollen in water) tensile testing. Fig. 10a shows the tensile strength of the prepared boards as a function of strain, and Table 2 summarizes the strength measurement results. The highest dry strength was observed with a cellulose/IL weight ratio of 1:3 (above $11 \mathrm{MPa}$ ). This correlates well with the SEM characterizations and density measurements, which showed that the 1:3 weight ratio formed the densest structure. In contrast, the strength of the 1:05 weight ratio specimen was below $1 \mathrm{MPa}$, indicating poor particle fusion. Extrusion significantly elevated the tensile properties. Dry strength was doubled to 20.4 MPa 
Table 2 Summary of mechanical properties of the IL-fused sawdust sheets

\begin{tabular}{|c|c|c|c|c|c|c|}
\hline & \multicolumn{6}{|c|}{ Sawdust: ionic liquid weight ratio } \\
\hline & $1: 0.5$ & $1: 1$ & $1: 1.5$ & $1: 2$ & $1: 3$ & $1: 3$ (extruded strand) \\
\hline $\begin{array}{l}\text { Tensile strength (condi- } \\
\text { tioned, } \mathrm{MPa} \text { ) }\end{array}$ & $0.6 \pm 0.3$ & $1.8 \pm 0.4$ & $5.4 \pm 1.1$ & $4.8 \pm 1.4$ & $10.4 \pm 4.3$ & $21.4 \pm 1.2$ \\
\hline $\begin{array}{l}\text { Young's modulus (con- } \\
\text { ditioned, MPa) }\end{array}$ & $201 \pm 26$ & $412 \pm 71$ & $748 \pm 68$ & $1161 \pm 118$ & $807 \pm 178$ & n.a \\
\hline $\begin{array}{l}\text { Strain at break (condi- } \\
\text { tioned, \%) }\end{array}$ & $1.1 \pm 0.3$ & $0.8 \pm 0.1$ & $1.2 \pm 0.2$ & $0.8 \pm 0.1$ & $2.4 \pm 1.1$ & $15.9 \pm 3.4$ \\
\hline Wet strength $(\mathrm{MPa})$ & $0.3 \pm 0.2$ & $0.7 \pm 0.1$ & $0.9 \pm 0.1$ & $2.2 \pm 0.3$ & $2.4 \pm 0.4$ & $4 \pm 0.1$ \\
\hline $\begin{array}{l}\text { Wet Young's modulus } \\
(\mathrm{MPa})\end{array}$ & $58 \pm 18$ & $76 \pm 10$ & $36 \pm 9$ & $39 \pm 4$ & $24 \pm 4$ & n.a \\
\hline Wet strain at break (\%) & $2.8 \pm 1.3$ & $2.5 \pm 0.2$ & $6.1 \pm 0.8$ & $19.3 \pm 3.6$ & $63.6 \pm 14.4$ & $16.3 \pm 1.0$ \\
\hline
\end{tabular}

(Table 2). The strength retention when wet (wet strength compared to dry strength) of the IL-fused specimens was between 16 and 50\%. The specimen made with 1:3 cellulose/IL weight ratio had $23 \%$ strength retention, which is typical of strength retention values reported for regenerated cellulose products (Zhang et al. 2001). This indicates that extrusion fused the particle together stronger, making a more uniform structure compared to the stationary dissolution approach.

All of the measured strain values of the stationary dissolved specimens were rather low (below 2.5\%), which is typical of wood-based material. The extrusion elevated the strain of the specimen to up to $16 \%$, which further indicates a uniform internal structure. The wet strength values differed substantially as a function of sawdust-ionic liquid weight ratio. At a ratio of $1: 3$, the wet strength of the stationary dissolved specimens reached up to $2.4 \%$, which is approximately $25 \%$ of the dry strength. In contrast, in the case of lower weight ratios, the wet strength was low. The wet strain at break varied from 2.8 to $63.8 \%$ (1:0.5 to $3: 1$, respectively) indicating that higher ratio procured a material structure that is more elastic when wet. The extrusion increased the wet strength to $4 \mathrm{MPa}$ that was $20 \%$ of the dry strength. Structural compaction as a function of weight ratio was also observed in the density values. The extruded specimen has the highest density $\left(1180 \mathrm{~kg} / \mathrm{m}^{3}\right)$ ( Fig. 10c). The densities of the specimens made with stationary dissolution at sawdust-ionic liquid weight ratios from 1:0.5 to 1:3 were from 342 to $1040 \mathrm{~kg} / \mathrm{m}^{3}$, respectively. Compaction was also seen in Shore D hardness, which was highest (70) for the 1:3 weight ratio specimen. As a reference, commercial MDF boards have typically Shore D hardness between 45 and 55. Water absorption values also decreased as a function of compaction ( Fig. 10c). The fluffy 1:0.5 specimen had very high, up to $250 \%$, water absorption, compared to the $100 \%$ water absorption of the $1: 3$ weight ratio specimen. Density, Shore D hardness, and water absorption values were not measured for the extruded specimen due to the shape of the specimen.

The tensile strength of commercial sawdust particle boards and MDF boards is reported to be 10-17 MPa and $18 \mathrm{MPa}$, respectively (McNatt 1973; Cai and Ross 2010). The water absorption value of sawdust particle board is approximately $130 \%$. 
Thus, the mechanical and water absorption properties of the prepared sawdust particle board are already close to the commercial reference materials.

\section{Conclusion}

A preparation process of sawdust-based particle board using the novel ionic liquid based fusion approach with [EMIM]OAc ionic liquid was studied. [EMIM] OAc fuses sawdust particles at high temperature (above $140{ }^{\circ} \mathrm{C}$ ). Thermal optical microscopy revealed that sufficiently high temperature $\left(>120{ }^{\circ} \mathrm{C}\right)$ is needed to start to dissolve the sawdust particles and to disrupt lignin bonding of the material. Sawdust-ionic liquid weight ratio is an important parameter, and it was observed that a 1:3 weight ratio gave the strongest sawdust boards. The use of extrusion-enhanced sawdust particles promoted dissolution and fusion, which further increased the mechanical strength of the material. Mechanical analysis showed that the IL-fused sawdust particle board has similar tensile properties to commercial materials. The studied method can be used to produce all-wood particle board without the use of resins that could evaporate in the room air during the end use. The all-wood particle board is a novel alternative to traditional resin glued particle boards, which can be utilized in interior and exterior construction materials as surface structured wall panels and furniture materials.

Acknowledgements This study was carried out as part of the CellFi (Conversion of Cellulose to Plastic) project funded by Business Finland and Finnish companies (Metsä Fibre Ltd, Metsä Board Ltd, Stora Enso Ltd, FL Pipe Ltd, Pölkky Ltd, and Versoul Ltd). The work was part of the Academy of Finland Flagship Programme under Project Nos. 318890 and 318891 (Competence Center for Materials Bioeconomy, FinnCERES).

Author contributions The manuscript was written through contributions of all authors. All authors have given approval to the final version of the manuscript.

Funding Open access funding provided by Technical Research Centre of Finland (VTT).

Data availability All research data utilized are shown in this article.

\section{Compliance with ethical standards}

Conflict of interest The article does not contain any conflicts of interests.

Open Access This article is licensed under a Creative Commons Attribution 4.0 International License, which permits use, sharing, adaptation, distribution and reproduction in any medium or format, as long as you give appropriate credit to the original author(s) and the source, provide a link to the Creative Commons licence, and indicate if changes were made. The images or other third party material in this article are included in the article's Creative Commons licence, unless indicated otherwise in a credit line to the material. If material is not included in the article's Creative Commons licence and your intended use is not permitted by statutory regulation or exceeds the permitted use, you will need to obtain permission directly from the copyright holder. To view a copy of this licence, visit http://creativecommons.org/licen ses/by/4.0/. 


\section{References}

Abeykoon C, Kelly AL, Vera-Sorroche J et al (2014) Process efficiency in polymer extrusion: correlation between the energy demand and melt thermal stability. Appl Energy 135:560-571. https://doi. org/10.1016/j.apenergy.2014.08.086

Atalla RH, Vanderhart DL (1984) Native cellulose: a composite of two distinct crystalline forms. Science 223:283-285

Cai Z, Ross RJ (2010) Mechanical properties of wood-based composite materials. Wood Handb wood as an Eng Mater chapter 12 Centen ed Gen Tech Rep FPL; GTR-190 Madison, WI US Dept Agric For Serv For Prod Lab 2010 p 121-1212 190:11-12

Croitoru C, Patachia S (2014) Biocomposites obtained from wood saw dust using ionic liquids. Acta Chem Iasi 22:113-134

Eriksson K-EL, Blanchette RA, Ander P (2012) Microbial and enzymatic degradation of wood and wood components, 1st edn. Springer Science \& Business Media, Heidelberg

Fan M, Dai D, Huang B (2012) Fourier transform infrared spectroscopy for natural fibres. In: Salih SM (ed) Fourier transform-materials analysis. InTechOpen, London, pp 45-68

FAO (2017) 2016 global forest products facts and figures Arvydas Lebedys (Ed), FAO-Food and agriculture Organization of the United Nations, Rome

Foston M (2014) Advances in solid-state NMR of cellulose. Curr Opin Biotechnol 27:176-184

Gholampour A, Ozbakkaloglu T (2020) A review of natural fiber composites: properties, modification and processing techniques, characterization, applications. J Mater Sci 55:829-892. https://doi. org/10.1007/s10853-019-03990-y

Graenacher C (1934) Cellulose solutions. Pat. US1943176

Grover PD, Mishra SK (1996) Biomass briquetting: technology and practices. Food and Agriculture Organization of the United Nations, Bangkok, Thailand

Isogai A, Usuda M, Kato T, Uryu T, Atalla RH (1989) Solid-state CP/MAS carbon-13 NMR study of cellulose polymorphs. Macromolecules 22:3168-3172. https://doi.org/10.1021/ma00197a045

Johnson DL (1969) Strengthening swellable fibrous material with an amine oxide. US US3447956A 3 pp

Khakalo A, Tanaka A, Korpela A, Hauru LKJ, Orelma H (2019) All-Wood composite material by partial fiber surface dissolution with an ionic liquid. ACS Sustain Chem Eng 7:3195-3202. https://doi. org/10.1021/acssuschemeng.8b05059

Khakalo A, Tanaka A, Korpela A, Orelma H (2020) Delignification and ionic liquid treatment of wood towards multi-functional high-performance structural materials. ACS Appl Mater Interfaces. https:// doi.org/10.1021/acsami.0c02221

Kilpeläinen I, Xie H, King A, Granstrom M, Heikkinen S, Argyropoulos DS (2007) Dissolution of wood in ionic liquids. J Agric Food Chem 55:9142-9148. https://doi.org/10.1021/jf071692e

Lahaye M, Rondeau-Mouro C, Deniaud E, Buléon A (2003) Solid-state 13C NMR spectroscopy studies of xylans in the cell wall of Palmaria palmata (L. Kuntze, Rhodophyta). Carbohydr Res 338:15591569. https://doi.org/10.1016/S0008-6215(03)00241-6

Le KA, Rudaz C, Budtova T (2014) Phase diagram, solubility limit and hydrodynamic properties of cellulose in binary solvents with ionic liquid. Carbohydr Polym 105:237-243. https://doi.org/10.1016/j. carbpol.2014.01.085

Li W, Sun N, Stoner B, Jiang X, Lu X, Rogers RD (2011) Rapid dissolution of lignocellulosic biomass in ionic liquids using temperatures above the glass transition of lignin. Green Chem 13:2038-2047. https://doi.org/10.1039/C1GC15522A

McNatt JD (1973) Basic engineering properties of particleboard. Forest Products Laboratory, Madison, WI

Mitchual SJ, Frimpong-Mensah K, Darkwa NA (2013) Effect of species, particle size and compacting pressure on relaxed density and compressive strength of fuel briquettes. Int J Energy Environ Eng 4:30. https://doi.org/10.1186/2251-6832-4-30

Nishino T, Arimoto N (2007) All-Cellulose composite prepared by selective dissolving of fiber surface. Biomacromolecules 8:2712-2716. https://doi.org/10.1021/bm0703416

Nishino T, Matsuda I, Hirao K (2004) All-Cellulose composite. Macromolecules 37:7683-7687. https:// doi.org/10.1021/ma049300h

Olsson A-M, Salmén L (1997) The effect of lignin composition on the viscoelastic properties of wood. Nord Pulp Pap Res J 12:140-144 
Pandey KK, Pitman AJ (2003) FTIR studies of the changes in wood chemistry following decay by brownrot and white-rot fungi. Int Biodeterior Biodegrad 52:151-160. https://doi.org/10.1016/S0964 $-8305(03) 00052-0$

Pizzi A (1982) Pine tannin adhesives for particleboard. Holz Roh Werkst 40:293-301

Pizzi A, Cameron F-A, van der Klashorst GH (1989) Soda bagasse lignin adhesives for particleboard. Preliminary results. In: Hemingway R W, Conner A H, Branham S J (eds) Adhesives from renewable resources. American Chemical Society, Washington, DC

$\mathrm{Pu}$ Y, Jiang N, Ragauskas AJ (2007) Ionic liquid as a green solvent for lignin. J Wood Chem Technol 27:23-33. https://doi.org/10.1080/02773810701282330

Roffael E (1993) Formaldehyde release from particleboard and other wood based panels, 1st edn. Forest Research Institute Malaysia Institut Penyeli dikan Perhutanan, Kuala Lumpur

Rusanen A, Lappalainen K, Kärkkäinen J, Tuuttila T, Mikola M, Lassi U (2019) Selective hemicellulose hydrolysis of Scots pine sawdust. Biomass Convers Biorefinery 9:283-291. https://doi.org/10.1007/ s13399-018-0357-z

Shmulsky R, Jones PD (2019) Forest products and wood science: an introduction, 7th edn. John Wiley \& Sons Ltd., Oxford. https://doi.org/10.1002/9780470960035

Tanaka A, Khakalo A, Hauru L, Hauru L, Korpela A, Orelma H (2018) Conversion of paper to film by ionic liquids: manufacturing process and properties. Cellulose 25:6107-6119. https://doi. org/10.1007/s10570-018-1944-7

Tejado A, Pena C, Labidi J, Echeverria JM, Mondragon I (2007) Physico-chemical characterization of lignins from different sources for use in phenol-formaldehyde resin synthesis. Bioresour Technol 98:1655-1663

Ulloa CA, Gordon AL, García XA (2009) Thermogravimetric study of interactions in the pyrolysis of blends of coal with radiata pine sawdust. Fuel Process Technol 90:583-590. https://doi. org/10.1016/j.fuproc.2008.12.015

Vítěz T, Trávníček P (2010) Particle size distribution of sawdust and wood shavings mixtures. Res Agric Eng 56:154-158

Wen J-L, Yuan T-Q, Sun S-L, Xu F, Sun R-C (2014) Understanding the chemical transformations of lignin during ionic liquid pretreatment. Green Chem 16:181-190. https://doi.org/10.1039/C3GC4 1752B

Woodings C (2001) Regenerated cellulose fibres, 1st edn. Woodhead Publishing Ltd and CRC LLC, Cambridge, UK

Zhang L, Ruan D, Zhou J (2001) Structure and properties of regenerated cellulose films prepared from cotton linters in $\mathrm{NaOH} /$ Urea aqueous solution. Ind Eng Chem Res 40:5923-5928. https://doi. org/10.1021/ie0010417

Publisher's Note Springer Nature remains neutral with regard to jurisdictional claims in published maps and institutional affiliations. 